Some Systems Aspects of Strategic Planning

Author(s): Rolfe Tomlinson and Robert Dyson

Source: The Journal of the Operational Research Society, Vol. 34, No. 8, Systems in O.R. First International IFORS and O.R.S. Meeting. Discussion Conference at Henly, U.K. 9-11 May 1983, (Aug., 1983), pp. 765-778

Published by: Palgrave Macmillan Journals on behalf of the Operational Research Society

Stable URL: http://www.jstor.org/stable/2581710

Accessed: 24/06/2008 05:03

Your use of the JSTOR archive indicates your acceptance of JSTOR's Terms and Conditions of Use, available at http://www.jstor.org/page/info/about/policies/terms.jsp. JSTOR's Terms and Conditions of Use provides, in part, that unless you have obtained prior permission, you may not download an entire issue of a journal or multiple copies of articles, and you may use content in the JSTOR archive only for your personal, non-commercial use.

Please contact the publisher regarding any further use of this work. Publisher contact information may be obtained at http://www.jstor.org/action/showPublisher?publisherCode=pal.

Each copy of any part of a JSTOR transmission must contain the same copyright notice that appears on the screen or printed page of such transmission.

JSTOR is a not-for-profit organization founded in 1995 to build trusted digital archives for scholarship. We work with the scholarly community to preserve their work and the materials they rely upon, and to build a common research platform that promotes the discovery and use of these resources. For more information about JSTOR, please contact support@ jstor.org. 


\title{
Some Systems Aspects of Strategic Planning
}

\author{
ROLFE TOMLINSON and ROBERT DYSON \\ ORASA Group, School of Industrial and Business Studies, University of Warwick
}

\begin{abstract}
This paper is concerned with the strategic planning process and the contribution that analysis can make to it. It develops a conceptual model of the strategic planning process based on the traditional control system model and identifies a number of basic elements of the process. Four groups of analytical tools are presented and their relevance to the planning process discussed. It is suggested that tools from the different groups may be used concurrently at different parts of the process, although the use of analytical tools in some parts of the planning process is not well established. Finally the role of the analyst in the overall planning process is discussed.
\end{abstract}

Key words: analysis, control, forecasting, modelling, planning

THE PURPOSE of this paper is to examine the potential role of analysis (operational research or systems analysis) in the strategic planning process of an organization. Elsewhere, Tomlinson ${ }^{1}$ has discussed the necessity of viewing effective O.R. as being the result of the interaction of two processes - the management process and the analytical process. It is only by understanding the underlying structure and interaction of the two processes that we can plan the interventions which lead to effective implementation.

We must start by giving some description of what we mean by strategic planning. In broad terms this may be described as the process of developing, and then updating, a world view against which major strategic decisions (major investments, structural reorganizations, policy formulation) can be set. All major decisions of this kind have to be taken in the light of some such world view, since it is often 5 years ahead and beyond that the real benefit from such decisions will become apparent. A few years ago there was great attention paid to the development of fixed scenarios within which optimization procedures were set, to say what the future would be. Strategic planning departments were set up, seemingly based on the idea that there was no difference in principle between the procedures needed for long-term planning of this nature and those required for normal budgeting based on 5-year rolling forecasts. But the long-term future cannot be predicted like that, and many such departments were subsequently closed. Strategic planning got a bad name.

But the common alternative, to work from the hunches and experience of staff with a reputation for judgement and far-sightedness, is also both dangerous and unacceptable. The guesses are still wrong, even though blame can be put on unpredictable changes in the environment. Indeed, it is the fact that change is so rapid, and the whole environment so complex and interconnected, that makes some explicit form of strategic planning essential. Strategic planning that does not take proper account of the potential of analysis and of analytical tools is scarcely worth the name.

This paper examines the problem from the point of view of the analyst. It assumes that there is a contribution to be made, and examines - in a holistic manner-what that contribution is. Tomlinson ${ }^{2}$ has suggested that any effective contribution will be made in one of three ways:

1. by improving the process by which decisions are made;

2. by improving some of the methods and tools and their usage during that process;

3. by improving the understanding of the participants in the process, as the only means of affecting the critical informal elements in that process.

Before the process can be improved, it must be understood and, if possible, modelled. Our understanding of strategic planning is that it is a continuous operation that bears close resemblance to a traditional control system. The next section sets out to explore the 
strategic planning process in these terms. Having described the overall process, we go on to examine the tools used by the analyst. We have found it helpful to classify them according to their purpose, rather than according to their point of input within the planning process. Finally we draw conclusions as to the overall role of the analyst, a major part of which is the creation of understanding in the minds of the planners. Nevertheless, it is only because of the key importance of analytical models that the analyst can also make his impact on the critical informal elements that go so far in determining policy.

\section{A CONTROL SYSTEMS MODEL FOR STRATEGIC PLANNING}

In this section a conceptual model of strategic planning and strategic decision-making is presented, using the principles of control systems. Many authors have discussed the validity of concepts of control in the study of administrative systems. In particular, Eilon ${ }^{3}$ has identified the management task as a control process, discussed some of the important ingredients involved in the management task and suggested fundamental concepts associated with the control function. Beer, ${ }^{4}$ Ackoff, ${ }^{5}$ and Hofstede, ${ }^{6}$ have developed systems models of the planning process, and Matsuda and Ifrano ${ }^{7}$ have recently published a perspective of planning literature that sets out some of the basic literature. Our approach is in some ways close to Hofstede; it is more specific than Eilon and less comprehensive than Beer in that it focuses exclusively on strategic decision-making.

\section{A Simple Control System}

The starting point for the development of the model is the simple control system shown in Figure 1 and based on diagrams presented by Phelan. ${ }^{8}$ An example, following Phelan, of a simple control system would be a room and heating system in winter, where it is desired to keep the temperature of the room at some predetermined level. The temperature is controlled by inputting heat from a source of warm air.

The controlled system consists of the room including the thermostat. The output of the controlled system, denoted OUT in the diagram, which in operational systems will be goods and/or services, in this case is the temperature of the room. This is likely to be a slightly varying quantity throughout the room, but it is usually sufficient to record the temperature at a single point by the recorder, in this case a thermostat. The recorded temperature, PERF, is the current level of the performance of the system. TARG here is the target temperature. The controller has two functions. One is to compare the current performance level, PERF, with the goal, TARG. The error or difference, GAP, is determined, and if this is sufficiently large, the controller employs a control algorithm, the second function, to determine the appropriate response or command, COM, which is transmitted to the final control elements. The final control elements call on the available resources, RES, and produce a controlled input, CONIN, to the controlled system. In this example RES is a supply of warm air. The final control elements consist of the apparatus necessary to call on the heat source, react to the command COM and input the appropriate amount of hot air, CONIN. In addition to CONIN, the temperature will be affected by

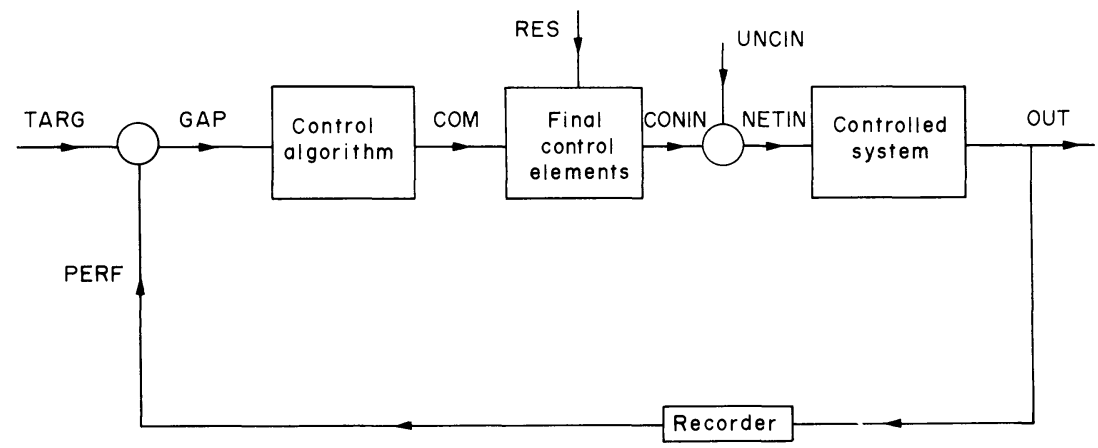

FIG. 1. Basic control system. 


\section{R. C. Tomlinson and R. G. Dyson-Strategic Planning}

heat gains and losses through windows and doors, and by heat from appliances, lights and occupants. These uncontrolled amounts of heat are represented by UNCIN, sometimes called the load on the system, so that the total heat input, NETIN, is the sum of CONIN and UNCIN (usually negative). The upper part of Figure 1 from TARG to OUT is known as the forward loop of the system and the lower part, which feeds back information on the output for comparison with the goal, as the feedback loop.

The system exhibits what Eilon ${ }^{3}$ suggests are the essential ingredients of any closed loop control process. They are:

a goal or standard,

a measurement task,

a feedback signal,

a control procedure,

a corrective action.

The goal or standard appears explicitly in Figure 1. The measurement task is carried out by the recorder. The feedback signal is the output, PERF, of the feedback loop. The control procedure corresponds to the functions of the controller, and the corrective action corresponds to the functions of the final control elements. Additionally, the availability of adequate resources, RES, is essential in order that the command from the controller can be converted by the final control elements into an adequate corrective action.

\section{Strategic Decision-Making as a Control System}

Having introduced the basic concepts of a control system illustrated in tactical situations, it is now possible to view the strategic decision-making process of the organization from this control systems perspective.

One interpretation of Figure 1 as a control system for strategic decisions would simply involve interpreting COM and CONIN (the controlled input) as representing strategic rather than tactical decisions. The implications of this would be that only the current performance of the system is assessed, and if this is not satisfactory when compared to the current objectives, then a strategic decision is taken. This interpretation typifies reactive decision-making as exemplified by the British government over the Falklands Crisis. The weakness with this model stems from the fact that strategic decisions affect not just the present, but more importantly, the future performance of the system-yet, decisions are taken based only on present performance. Furthermore, strategic decisions usually take time to have an impact, so that corrective action may be too late. The implication of this is that a strategic decision process requires not just measurement of present performance, but also prediction of future performance. It should be proactive.

The above simple interpretation of Figure 1 is, therefore, inadequate and, as a minimum, it is necessary to obtain predictions into the future of the performance. These predictions are denoted as OUT $H^{\prime}$ and PERF $H^{\prime}$, where $H$ denotes values up to a future horizon $H$ years ahead, and the dash indicates that these are predicted values rather than actual outcomes. The goal must be extended to an objective set including future objectives, denoted by $\mathrm{OBJ} H$. Performance measures may need development for some of the objectives. The difference or gap becomes a prediction, GAP $H^{\prime}$. In order to produce OUT $H^{\prime}$ and PERF $H^{\prime}$, it is now necessary to have some kind of model of the controlled system, as it is not possible to experiment with the existing system to deduce the effects of future possible conditions, which are outside the range of current experience. Additionally, the system may itself be changing as previous strategic decisions begin to make a full impact. The use of the word 'model' above is not meant to imply that a formal, quantitative - possibly computerized-model of the organization is a necessary part of every strategic decision-making process. The model represents whatever process is used to predict future performance of the system.

Further elaboration of the control system is necessary with regard to the control algorithm. In tactical situations this may be an automatic or semi-automatic procedure. In this case, it involves the formulation, evaluation and selection of strategic options. To 
carry out this evaluation, again a model of the controlled system is required, as experimentation cannot be carried out on the real system. Evaluation of a single option will involve incorporating the proposal into the model of the system and predicting PERF $H^{\prime}$ and GAP $H^{\prime}$ (by comparing PERF $H^{\prime}$ with OBJ $H$ ) for the revised system. The evaluation must also take into account the future resource availability RES $H^{\prime}$ and a check on the feasibility of implementation (e.g. the likelihood of obtaining planning permission for a major development). The evaluation of a single option thus involves a similar process to the evaluation of the existing system. If several options are under consideration, then ideally all possible hypothetical systems made up of combinations of options should be evaluated.

A final major modification to Figure 1 occurs owing to the nature of $\mathrm{OBJ} H$, the future objectives. The search for strategic changes occurs as a result of comparing OBJ $H$ with PERF $H^{\prime}$. If the difference GAP $H^{\prime}$ is judged to be significant, then strategic decisions may be taken which by definition are significant, have enduring effects and are difficult to reverse. The setting of $\mathrm{OBJ} H$ can thus lead to significant changes in the future performance of the organization so that it is itself a strategic decision. Clearly then, the strategic decision-making process of the organization includes the determination and review of $\mathrm{OBJ} H$. This process will also be influenced by the predicted future performance of the system, PERF $H^{\prime}$. The control system representing a strategic decision-making process is shown in Figure 2.

The most noticeable difference between Figures 1 and 2 is the addition of a second limb to the forward loop. This limb includes the formulation and evaluation of strategic options and corresponds to the control algorithm in Figure 1. The forward loop, including the new limb, can be thought of as the strategic planning process. On this loop $\mathrm{COM}^{\prime}$ represents a strategic option that is to be fully evaluated. The model of the final control elements represents the process of checking the feasibility of implementing the proposal, including checking the availability of resources. CONIN $H^{\prime}$ represents the necessary change to the system model, and UNCIN $H^{\prime}$ represents the predictions for the uncontrolled input or load. An important feature of the system is that this uncontrolled input is no longer entirely independent of the controlled input. These uncontrolled inputs may represent effects due to competitor strategies, government policies, trade union activity and economic conditions generally. These are not in control of the decision-makers, but their impact on the system can often be influenced by the strategies proposed and adopted. We shall refer to the determination of these inputs as impact assessment.

The upper limb of the forward loop represents the actual result of adopting strategy CONIN $H$. The final control elements become the implementation process for the new

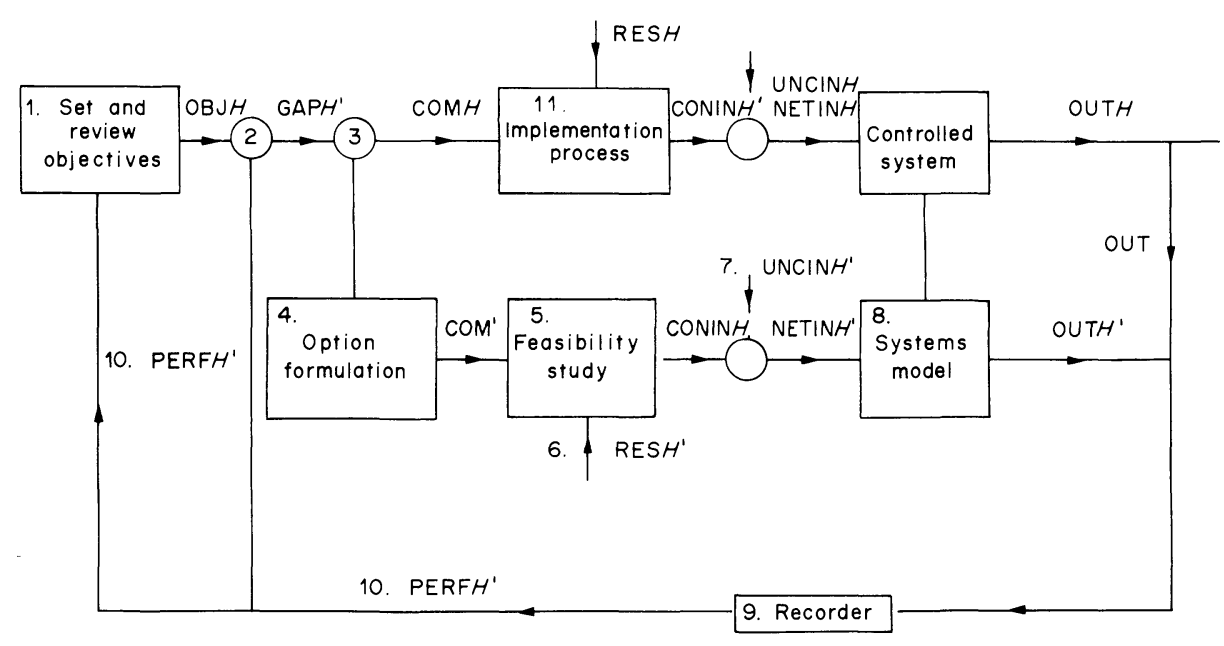

FIG. 2. Control system for strategic decision making. 
strategy. UNCIN $H$ are the outcomes of the uncontrolled variables, and OUT $H$ is the actual performance of the system.

This view of strategic decision-making highlights many of its complexities. Evaluating a strategy requires production of OUT $H^{\prime}$, the future performance of the modified system. To achieve this, not only is a satisfactory model of the system required, but also forecasts of the uncontrolled inputs, $\mathrm{UNCIN} H^{\prime}$, are required. The future values of these elements are themselves unknown, uncertain and to some extent may be unforeseeable. Forecasting the future performance of the system will thus be difficult. In particular, production of a single forecast for UNCIN $H^{\prime}$ under the most likely assumptions will be inadequate, as the chance of it turning out at its most likely value will be minimal. Future availability of resources RES $H^{\prime}$ must also be taken into account. (For public sector organizations, this will include governmental funding - a critical factor.) OUT $H^{\prime}$ will therefore be uncertain as well as multi-valued, and the feedback signal, PERFH', will be of considerable complexity. One result of this complexity in evaluating future performance is that the strategic decision-making process might (or should) aim to engineer a structure to the organization which would perform well, not only in foreseeable situations where future performance per se might be predicted, but also in unforeseeable situations. The latter can be sought be seeking to design a flexible structure for the organization. This line of argument has implications for the construction of the objective set OBJH (see Ansoff ${ }^{9}$ for a discussion of flexibility objectives).

This complexity will also exhibit itself in the comparison of PERF $H^{\prime}$ with OBJ $H$. Determining the difference, GAP $H^{\prime}$, is called gap analysis. Clearly GAP $H^{\prime}$ will be multi-valued and uncertain as it depends on PERF $H^{\prime}$, and it is a difficult task to represent it in a meaningful way. It is also difficult to determine whether the gap is sufficiently large for a search for closing it, one of the triggers of the formulation process, to continue.

The control systems model would appear to be over-restrictive in the way that strategic options are generated, as the formulation process is apparently triggered only when a significant gap is identified. In most organizations, however, the objective set $\mathrm{OBJ} H$ will include not just specific long-run targets and goals, but ideals to be strived for and desirable structures to be sought. Ackoff ${ }^{10}$ would also include stylistic objectives, which would indicate that simply taking part in a particular kind of activity was acceptable (e.g. acquisitions are fun). Additionally, external or internal events and predictions may lead to a review of the objective set. Creative thinking may lead to changes in objectives and suggest new opportunities. The search for new strategies should therefore be continuous, although the adoption may be intermittent.

\section{Elements of the Strategic Planning Process}

Having now developed a conceptual model of strategic decision-making and planning, using control systems principles, it is possible to enlarge Eilon's notion of essential ingredients. From Figure 2 the following elements can be identified:

1. Objective setting and review

2. Gap analysis

3. Selection

4. Option formulation and screening

5. Feasibility check

6. Resource assessment

7. Impact assessment

8. System model

9. Recorder

10. Feedback singal

11. Implementation process.

Many of the above are self-explanatory, but some warrant further elaboration.

A screening mechanism is required to select in the formulation process those strategies that warrant a fuller evaluation. The impact assessment is the process of determining the 
current, UNCIN, and future, UNCIN $H^{\prime}$, impact of the uncontrolled inputs. The recorder collects information on the current state of the organization, OUT, and on future states, OUT $H^{\prime}$, and determines the feedback signal, PERF $H^{\prime}$.

The list of elements, coupled with the conceptual model, can be used to guide the engineering of the organization for effective strategic planning and decision-making. This represents an approach to effectiveness similar to that proposed by Dyson and Foster, ${ }^{11}$ although their approach was developed from studying normative writings and from discussions with practising planners, rather than from a single theoretical framework. A fuller development of the control systems approach to strategic decision-making has been presented by Dyson. ${ }^{12}$

The following section introduces and discusses the various groups of tools available to the analyst and links them to the elements of the planning process.

\section{THE ANALYST'S TOOLS}

In this section we shall examine the range of tools available to the analyst which will enable him to improve the various steps in the strategic planning process described in the previous section. We shall do so, however, by grouping the tools according to their immediate purpose, rather than by their relation to the process. Indeed, as will become apparent, there is no simple relationship between these analytical tools and the steps in the process. Tools of different kinds may be used in any one stage of the process.

We shall consider the tools under four headings:

data and intelligence,

models of behaviour,

projections,

decision aids.

There appears to be a clear logical sequence between the groups, which is more apparent on paper than in practice. If a single planning study were to be undertaken, then the steps of analysis would follow this sequence-but if one has a strategic planning process going on on a continuous basis, analysis tends to be drawing on all four groups at the same time.

What is the role of the tools in the planning process? Basically, our analytical tools serve two purposes - one negative and one positive. In a negative sense, they test the validity of deductive processes used in the planning process. Will the data stand this interpretation? If this happens, will that be the consequence? On the positive side, the tools greatly increase the power and range of deduction. Because of their ability to deal with complexity, the tools can give certainty in the place of speculation-but the range of that certainty is still strictly delimited. It is only the certainty of deduction from assumptions. The tools cannot make the future more certain. To make wrong deductions from any assumptions is dangerous. But correct deductions from doubtful assumptions also have their danger.

\section{Data and Intelligence}

All planning depends on information. Information collection, manipulation and retrieval must always be a primary concern of the analyst. Not only is information processing an analytical task, the information itself is the bedrock on which most analysis builds. There are at least six activities within this overall heading to which we need to pay some attention.

\section{Data collection}

The data that one might need for strategic planning is unbounded - there are no limits to what might become relevant to the future success of current strategies. There will always be heavy reliance on managerial intuition and ad hoc studies. But there is also the need to provide a solid base of essential facts, even if some of those essential facts are unobtainable in an ideal form and have to be substituted by secondary data, or left for unsupported intuition. 


\section{R. C. Tomlinson and R. G. Dyson-Strategic Planning}

Part of the data base will be internal, and thus in a sense private to the organization undertaking the planning. This will cover normal (historical) statistical data, as well as data collected specifically in the planning process. Just as important as information on the 'known' past is that on the 'knowable' future - e.g. information on plans and intentions.

Part of the data base will be concerned with the external environment, and the further ahead you look the greater is its relative weighting. Information about the 'known' past is, in theory, equally accessible to everyone. Much data is published in statistics, much is available in a variety of reported forms, some is available to research. What is available depends on the effort given to collecting it, and the objectives that the collector has been set. This latter will certainly be affected by its anticipated use, and this requires some knowledge of the models, projections and overall objectives of the work. The complex cross-linking between tools and process has already begun. Information about the 'knowable' future has to be collected in the same way as much about the past-but the problems of converting it into usable data often rests heavily on the introduction of other tools.

Over the whole issue of data collection hang the two questions-What? How much? Information always costs money, and much of the information collected will inevitably be wasted. Effective advice depends on being able to make judgements on what data to collect, given its availability and potential value - a particular skill, as we see it, of the operational research analyst.

\section{Collating and summarizing}

It is relatively easy to produce simple - and apparently comprehensible - summaries of data that over-simplify and positively mislead. The use of most summary indices usually rests upon unspoken assumptions implying a continuity of behaviour with the past. One of the problems for the analyst is to ensure that summary data does, in fact, give the correct information. This is important at all stages of the planning process, but nowhere more important than in the first stage of objective setting and reviewing. For medium-term investment planning, many organizations have got past the belief that a single index will indicate whether the investment should go ahead. For management of the economy, such beliefs often appear still to hold. To summarize data for its long-term importance, choice of appropriate indices is even more important.

\section{Comparison and accuracy determination}

Some data is not worth the paper it is written on-other has value which is quite different from its apparent stated meaning. In working with data of this kind, one needs to know enough about the data, and the methods by which it has been collected, to be able to make some statements as to its degree of reliability. This may be a question of statistics, but it is often a question of understanding the purpose of the information. Thus if one is using internal planning data, it may be extremely important to find out whether a figure is a target or a best estimate. To confuse the two can be dangerous. A good deal of cross-checking and comparative analysis is likely to be necessary.

\section{Storage and access}

Data is only of value if it can be used, and we are currently in a technological revolution which is transforming the ease of access of planners to their own data. It is essential that storage and access systems be designed by people who know how the information is to be used, and it is important to ensure that the person who retrieves data knows what he is retrieving. It is perhaps particularly important to remember that much of the information stored and accessed by the planners will be the result of their own work, such as their scenarios and the standard output of their models. Clearly this is of great importance at many stages of the planning process.

\section{Updating}

The most difficult, and perhaps the least rewarding, aspect of data collection and 
intelligence is that of updating. Not simply because the data is drawn from so many sources, but because it will be used by so many of the analytical tools and for the creation of so much secondary data that there is great danger of introducing inconsistencies at a later stage of analysis. There is clearly a major role for the analyst here.

\section{Trend analysis}

The final stage in the capture of data concerning the 'known' or 'knowable' worlds is the establishment of trend analysis, which not only establishes patterns, but more particularly identifies changes in those patterns. Such trends may well be the basis for prediction models, but this detection of changing patterns remains one of the key factors in providing useful intelligence about the outside world.

The foregoing has covered very briefly a wide range of tools available to the analyst in helping to provide better data, and access to that data, for those involved in the planning process. A set of tools does not define a process, and we have defined neither the whole role of the analyst in relation to data, nor its importance in the overall planning process, where it is pervasive. At every stage of the planning process there is both recourse to data, and the creation of new data. The output of possible plans and scenarios, obtained within the planning process, may be no less important than the results of other people's intentions and speculations. The internal creation of data in this form, however, creates significant problems in relation to the assumptions made in its creation. Clearly it is necessary, if there is a possibility of using such data at a future data, to know what those assumptions have been.

\section{Models of Behaviour}

We cannot in general know what will happen in the future. So far as we can make any statements at all, they must stem from a series of beliefs, not simply about the ways things are and are developing, but also about the underlying causal mechanisms. In everyday life, and in the strategic planning of many organizations, these beliefs are often unspoken and inconsistent. They may result from experience (but is that experience relevant to a very different future?), from a belief about what governs behaviour (whether political or pholosophical), or from a desire for a particular outcome. The role of the analyst is to try and make these understandings explicit, in the form of a model which can be criticized, and .which can be used to answer the critical 'what-if' questions that lie at the heart of all strategic planning exercises.

The models that one usually considers in this context are models of the firm (e.g. corporate planning models) or of the external environment (e.g. economic forecasts) or of their interaction (e.g. gaming). Before we consider these, we must, however, look at 'concept models', which explore the consequences of assumptions that are often madealmost blindly - within corporate and environmental models.

Let us start with one of the commonest assumptions built into economic models, but also into models of technological growth - the economies of scale. The belief that an increased scale of operation will lead to operational savings through a reduction in proportional overheads is endemic. Engineers and economists both happily use equations of the form:

$$
\text { Cost per unit output }=(\text { Scale })^{-b} \text {. }
$$

The measures chosen for output, scale and the value of the constant $b$ are based on a variety of assumptions or observations. There is a need to justify such assumptions and to check their likely validity for the future.

Or take the question of market penetration. Given a new technology or product, just entering the market, how rapidly will it develop, and how quickly will it be overtaken by a competitor? And how rapidly will production costs decrease, owing to managerial improvements and/or technological change? All these are questions that have to be answered because they have - potentially at least - a major part to play in the validity of the corporate model that explores the consequences of possible action. Not all concepts 
are necessarily modellable, but as many as possible should be identified and tested. Curiously enough, it may sometimes be easier to get a more reliable picture of the behaviour of another organization - based on reasonably objective observation - than of ones own organization, where observation tends to be distorted by assumptions as to what should be.

In general, the modelling work relative to strategic planning falls into two parts- that which relates to the internal activities of the organization, largely based on private, internal data, and that which relates to the environment, based on external statistics and intelligence. There have been those in the past who have sought, for reason of consistency or convenience, to establish one single model to explore all possible patterns of behaviour of the organization and its environment. Such an approach has grave disadvantages and has generally proved infeasible. For a variety of reasons the emphasis has tended to shift towards developing suites of models built to examine particular aspects of the problem, which can be used together to obtain an overview. Moreover, all models do not require the same level of detail, and the data employed may not justify great detail. Small models are often extremely convenient in discussion and are easy to alter. Because they lack detail, they are likely to be used in conjunction with more elaborate models, which can explore particular aspects of the subject in detail. But these simple models are of particular importance in enabling planners to explore ideas to understand the pattern of likely behaviour in different circumstances. In other words they create understanding.

The internal models may consist of models of many kinds: production, financial, market, personnel models may all be necessary. Detailed plant models may sometimes be required. Often the models will be the same as those needed for medium-term planning; some will be different.

The external models will also depend on many factors. Some will try to predict the behaviour of the economy under certain conditions. Some will be related to the industrial sector concerned, some to one particular market. Others might be concerned only with energy, housing or money flows. At first sight there appears to be a great deal of unnecessary duplication in the models used in different organizations. But there are also instances of organizations unwilling to go to the expense of constructing their own models and unable to find models outside, even though there is a general need for them. There are many reasons for this. A number of the models developed have been paid for by government, are directed towards government policy and tackle questions at a level too macro for organizational planners. Secondly, planners are accustomed to working with reports rather than with models. This follows partly from their training and experience, which is generally not analytical, and partly from the fact that until recently the manipulation of models was the preserve of the computer systems analyst or operational researcher. Now that models are becoming more user-friendly, enabling a planner to obtain his own reports and results, using his own assumptions, the situation is rife for change. Thirdly, in a competitive world it is difficult for organizations to get together and agree on a common approach, even if they have much to gain from the model which they can use to generate their private beliefs. Where such models have been built, they have tended, therefore, to be speculative ventures on the part of consultancies, or activities funded by central government. There is great value to be obtained from research directed towards models for use by individual organizations, but commonly funded.

Finally, the importance of a good modelling suite in contributing to the planning process needs emphasis. Ideas of relative importance of cause and effect are central to strategic planning, and the use of analytical models is essential for reasonable understanding. As we have emphasized, the use of models is universal in planning, but many models used are commonly instinctive and often inconsistent, and these are often used in conjunction with rules of thumb which are extrapolations of present experience rather than based on underlying relationships. The analyst is as much to blame for this attitude as the planner-for his naïveté, for example concerning the usefulness of large mathematical optimization models, has often been disastrous - but there is fear of analysis in this area which needs to be overcome. 


\section{Projections}

Given data and models of behaviour, combined with insight and intuition, the analyst is in a strong position to assist in making projections of possible futures. The planners can then compare the projections with their desired outcomes and thus start to identify possible courses of action.

It is important to realize that the potential contribution of the analyst is much greater than the sum of the tools which he can employ. As usual, that contribution can be both creative and critical.

In his creative role, the analyst is concerned with generating possible futures and in identifying actions or policies that might make those futures possible. He has many tools that he can use to this end. It may be possible, though rarely, to use formal, extrapolating, forecasting techniques. He may be able, through the use of programming techniques, to propose an 'optimum' mix of investments to achieve a given outcome. More often he will be exploring ways of trying to pull together a set of subjective, expert opinions into a consistent scenario. Techniques such as gaming, Delphi and cross-impact analysis can be of great use in this connection, but it is often the general analytical skill combined with simple techniques that is needed. Indeed, there may be frequent further references to models of behaviour at this stage.

One of the major tasks in the analyst's critical role is to identify what is forecastable and what is not; what has some statistical interpretation and what is speculation (thus the population of Europe in AD 2000 is forecastable with reasonable accuracy-failing a nuclear holocaust-but the birth rate in that year must be speculation). The main critical effort is, however, likely to be directed towards the question of ensuring that consistent scenarios are developed which will describe possible states of the environment and feasible states of the organization within it. There are few special tools for determing consistency and feasibility - although there has been some use of morphological analysis (and much of networks, although they are hardly special). For the most part, the analyst will have again to draw on the models of behaviour as his main tool-kit.

\section{Decision Aids}

If the future success of strategic options could be judged on the basis of a single index, the provision of decision aids for selection would be straightforward. Indeed, threshold levels for rate of return on investments and target payback periods are examples of simple decision aids.

In general, strategic decision problems are characterized by multiple objectives, risk and time lags between decision and outcome, and in such situations simple aids are found wanting. Time lags can be handled by discounting methods. Uncertainty can be accommodated, for example, by risk analysis, risk adjusted discount rates and robustness analysis. Methods abound, but there is little agreement at present on either whether or in what circumstances uncertainty can be formally modelled and how it can be presented to decision-makers. The field is still open to controversy and active research, and the same is true of multi-criteria decision-making, where current activity is evidenced by the existence of a Working Group of the Association of European O.R. Societies. As with risk, a variety of approaches to accommodating multiple objectives has been proposed. These include multi-attribute utility theory, multi-objective programming, the analytical hierarchy approach, multi-dimensional scaling and cost benefit analysis. Some approaches such as fuzzy set theory can encompass both uncertainty and multiple objectives.

In concluding this section of the paper, it may be helpful to see whether we can draw any general conclusions as to the use of tools in the planning process. It should be clear from the foregoing presentation that there has been no attempt to use the tools to replace some parts of the planning process. Indeed, the very way in which we have placed the various tools and models in groups makes this clear. Figure 3 is a first, and tentative, attempt to show how different tools have a part to play in each element of the process. 
Tools from the different groups may be used concurrently at different parts of the process, and one or more groups has a part to play at every stage of the process.

For some entries in Figure 3, the ticks are related more to potential than accepted usage. For example, models for objective setting and option formulation are less well-established than the use of a system model for evaluation purposes. The use of gaming for impact assessment is often more a matter of speculation than fact. Finally, changes in computer technology highlight the importance of the decision on the content and nature of the feedback singal.

The very fact that tools have a contribution to play at every stage of the planning process indicates that the strategic planning process must necessarily be deficient if it does not make use of them. In the absence of such analytical tools, the planners are driven to use cruder and less reliable forms of analysis, or to ignore analysis altogether in favour of hunch and opinion. As a corollary to this, if planners are to make effective use of the tools, they should know what they are and have some information as to what they can do. The way in which this requirement can be satisfied is one of the main themes of our final section.

\begin{tabular}{|c|c|c|c|c|}
\hline & $\begin{array}{l}8 \\
0 \\
0 \\
\delta \\
0 \\
0 \\
0 \\
0 \\
0 \\
0 \\
0\end{array}$ & 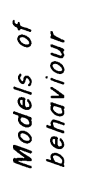 & $\begin{array}{l}n \\
\delta \\
\vdots \\
0 \\
0 \\
0 \\
0\end{array}$ & $\begin{array}{l}5 \\
5 \\
5 \\
80 \\
0 \\
0\end{array}$ \\
\hline Objective setting, review & $\checkmark$ & $\checkmark$ & $\checkmark$ & d \\
\hline Gap analysis & & & & $\checkmark$ \\
\hline Selection & & & & $\checkmark$ \\
\hline Option formulation and screening & $\checkmark$ & $\checkmark$ & $\checkmark$ & $\checkmark$ \\
\hline Feasibility & $\checkmark$ & & $\checkmark$ & \\
\hline Resource assessment & $\checkmark$ & $\sqrt{ }$ & $\checkmark$ & \\
\hline Impact assessment & $\checkmark$ & $\checkmark$ & $\checkmark$ & \\
\hline Systems model & & $\sqrt{ }$ & & \\
\hline Recorder & $\checkmark$ & & & \\
\hline Feedback signal & $\checkmark$ & & & $\checkmark$ \\
\hline Implementation process & & & & $\checkmark$ \\
\hline
\end{tabular}

FIG. 3. The relationship of analytical tools to the elements of the planning process.

\section{THE ROLE OF THE ANALYST}

Having examined the processes involved in strategic planning and the variety of tools that may be used to help in those processes, we now turn our attention to the analyst himself and consider the role he fulfils within the overall planning process. It should be emphasized from the outset that this is a matter on which there has been a good deal of debate, which shows little sign of being generally resolved. The debate hinges on the question of whether the analyst is essentially an interventionist (the classical viewpoint) or a model-builder (the academic approach). In other words, whether the model is the analyst's raison d'être or whether it is merely a tool (albeit a distinctive tool) which enables him to do his work, but which is not the essence of that work.

Traditionally, in the U.K. at least, the classical position has always been maintained. O.R. is solving problems, providing a service to decision-makers. It cannot be carried on in the computer room as an abstract objective exercise. On the other hand, there is also wide adherence to the academic view. O.R. is commonly taught, certainly outside the U.K., as the science of model-building, and scant and secondary attention is given to understanding the intellectual basis underlying the craft of scientific investigation in social organizations. 
The classical attitude to models is clear-cut. The model cannot be separated from the analyst. Model-building is a skill at which analysts have to be competent, but mistakes in building imperfect models are no more serious than mistakes which arise from their improper use, or because the person using them lacks sufficient knowledge either of the decision situation or of the assumptions etc inherent in the model. The analyst must take responsibility for the application of the model. Indeed, from the strictly classical point of view, the model can only be properly applied by someone who is working on a continuing basis in the decision-maker's or planner's organisation.

We basically adhere to the classical view, but it is necessary to recognize that it is difficult to justify in its purest form. Most O.R. groups do prepare standard models which, after testing, are handed over for unaided management use. The model is separated from its maker. However, the separation is seldom total. The analyst keeps an eye on what is happening, checks to see whether situations alter to require modification and gives assistance when things appear to go wrong. Although he loses responsibility for the operation of the model, he retains overall responsibility for ensuring that it remains serviceable and is used correctly.

When we come to strategic planning, the need to have some 'analyst-free' models available for general use is of increased importance. We have already argued the case for having a range of models (e.g. of the economy, energy) which will be generally available to planners in industry to enable them to explore the possible consequences of future change. In the U.S., the use of such free-standing models in widespread; indeed, they are legally incorporated into the public planning processes. Any model used in a major policy analysis has to be stated and specified, and it has to be available for general criticism, analysis and debate. The models themselves are, more often than not, created by consultants whose task is formally completed when the model is tested and running. Many such consultants have claimed that their models can only be used by themselves, but such an attitude is probably untenable in the long run, since effective use needs closer involvement with the affairs of the department concerned than any organization will guarantee to any single consultant. Thus, in the U.S., there are many 'free-standing' models for policy analysis and, as a consequence, problems of model validation have become increasingly severe. A great deal of consideration is now being given to specifying conditions that model-builders have to satisfy in order to have their models accepted.

Even if the general questions of model validation can be overcome (and it is questionable whether the acceptance of 'reliable' validation methods would ever be financially acceptable to clients), there still remains the question of use. Almost by definition, models which are prepared in this way are sophisticated and complex, require large amounts of data, and many assumptions are hidden within their inner working. Moreover, the conditions under which the model will be applied will, inevitably, differ from those which the model-maker assumed would be in force. Assumptions will, therefore, have to be modified, certain required conditions broken. The modification and use of a model in these circumstances can only be satisfactorily undertaken by a professional analyst. Thus, the existence of standard models by no means eliminates the need for the planning team to receive advice and assistance from an analyst, even if he is not the author of the model that is being used.

What then is the position of the analyst in relation to the planning team? It is difficult to make any sensible comments on this without some discussion of what that team consists of and the way in which its work is organized. There is no standard pattern for this; it must be organization dependent. A multi-national organization, working in many products, will inevitably need a team of people knowledgeable about world trade, supported by experts in production, personnel etc. Organizations whose output is confined within one country and a limited range of products will be able to operate with a much smaller, more simply structured team. Often there will be a relatively small number of full-time planners whose role may be much more that of collators and coordinators, drawing on the knowledge and expertise of planners in functional departments. Since planning of all kinds is essentially a management activity, the team needs to be well-placed 
within the organization and have the active involvement of management at the highest level. It may simply be one man. There is no single organizational pattern that will fit all cases.

Similarly, there is no single form of administrative process which can universally be applied. We have described the necessary elements in a strategic planning process in the first section, but that description is not intended to provide a substitute either for an organization chart or for the design of an administrative work schedule. It does, rather, provide an effective check list of activities that must be undertaken if planning is to be effective. Effective strategic planning demands a regular and thoroughgoing review of all possibilities, even though a high proportion of the work is devoted to once-off or ad hoc proposals for investment or policy. Unless there is a carefully worked out background world view, the analysis for major decisions will remain ad hoc, contradictory and wasteful. Again we must emphasize that there is always some world view, and some background model, against which decisions are taken. Our first plea is that it should be explicit and consistent. It is difficult to see how this can be achieved without analytical assistance. It could be argued that our type of model constitutes the only useful kind of generalization that is possible when describing the overall process.

What can the analyst add to the skills of the strategic planner? In considering this question, we immediately point to the fact that the analyst has a specific and irreplaceable service role to play, and that from this role he becomes the personnal possessor of knowledge that may make him, as a person, a valuable member of the planning team as such. Whereas in the latter role he should be prepared to react and take up responsibility at short notice in times of crisis, his primary professional skill remains that of analyzing and innovating, i.e. he is one stage removed from the preparation of an urgent brief for the chairman. His main specialist contribution lies in analytical skill-in the ability to anticipate and formulate problems, undertake relevant analysis, identify, develop and apply appropriate models, and explore alternative practical solutions. In doing this he provides the planners concerned with continuity (through the data base and the models) and understanding (accumulated through a range of studies using the models under different assumptions). It is a creative role in its own right, and an 'on-call' relationship with the planning team will not suffice.

In order that he himself should be able to fulfil this role, the analyst needs to understand the problems faced by the planning team; he needs to anticipate their needs so as to develop tools and models in time for use, and he has to submit all proposals to critical appraisal. The role may be difficult and certainly cannot be carried out unless contact with the planners is regular and frequent. Whether he becomes a member of the planning team in his own right or remains the provider of a service will depend on the organization and on his own social and managerial skills. By right of being an analyst, he does not have an automatic right to inclusion in the team (nor does it provide an automatic reason for exclusion). In this sense, the analyst's role in relation to the planners is the same as it is in relation to other management functions. In particular, he has to manage the interaction between the management and the analytical process, bearing in mind that he is equally concerned with the overall process and the understanding of the actors in that process as he is with tool (model) development. It is a systems involvement.

\section{REFERENCES}

${ }^{1}$ R. C. Tombinson (1980) Doing something about the future. J. Opl Res. Soc. 31, 467-476.

${ }^{2}$ R. C. Tomlinson (1980) Intervention-the interface between reality and thought. Operations Research Proceedings, 1980. Springer, Berlin.

${ }^{3}$ S. EILON (1979) Management Control. Pergamon Press, Oxford.

${ }^{4}$ S. BeER (1981) The Brain of the Firm, 2nd edn. Wiley, London.

${ }^{5}$ R. L. ACKoff (1970) A Concept of Corporate Planning. Wiley-Interscience, New York.

${ }^{6} \mathrm{G}$. HofsTEDE (1983) Management control of public and not-for-profit activities. Accounting, Organisations and Society 6, 193-209.

${ }^{7}$ T. Matsadu and M. Hirano (1983) A perspective of planning literature. Eur. J. Opl Res. 12, 138-145.

${ }^{8}$ R. M. Phelan (1977) Automatic Control Systems. Cornell University Press, New York. 
Journal of the Operational Research Society, Vol. 34, No. 8

${ }^{9}$ H. I. Ansoff (1968) Corporate Strategy. Penguin, England.

${ }^{10}$ R. L. Ackoff (1978) The Art of Problem Solving. Wiley, New York.

${ }^{11}$ R. G. Dyson and M. J. Foster (1983) Effective strategic planning revisited. Eur. J. Opl Res. 12, 146-158.

${ }^{12}$ R. G. Dyson (1982) Strategic decision-making: a control systems perspective. Working Paper 81/82-4-27, Graduate School of Business, University of Texas at Austin. 